\title{
Psychosocial Adjustment to a Lower Limb Amputation Ten Months After Surgery
}

\author{
Susana Pedras \\ University of Minho \\ Rui Carvalho \\ Centro Hospitalar do Porto, Porto, Portugal
}

\author{
Estela Vilhena \\ M. Graça Pereira
University of Minho
}

Polytechnic Institute of Cávado and Ave and University of Porto

Objective: This longitudinal multisite study examined the influence of demographic characteristics, psychological reactions, functionality, coping strategies, and social support on psychosocial adjustment to lower limb amputation 10 months after surgery. Method: Of an initial referral of 206 Portuguese patients, a sample of 86 patients who underwent a lower limb amputation due to Diabetes Mellitus Type II were evaluated during the hospitalization that preceded surgery (t0) and at inpatient follow-up consultations, 1 (t1), 6 (t2), and 10 months (t3) after surgery. Results: Higher levels of anxiety symptoms and functionality at presurgery were associated with lower social adjustment to amputation and with higher adjustment to the limitations ( $\mathrm{t} 3$ ) respectively. Traumatic stress symptoms (t1) were negatively associated with general and social adjustment, and with the adjustment to the limitations (t3). Perceived social support (t2) mediated the relationship between traumatic stress symptoms (t1) and adjustment to the limitations ( $\mathrm{t} 3$ ). Male gender was associated with a higher anxiety and depression symptoms $(\mathrm{t} 0)$ and with a higher level of functionality (t1). Male gender was associated with functionality at presurgery and postsurgery, and with anxiety and depression symptoms of presurgery. Implications: Results support the need to improve psychological screening and early treatment of anxiety symptoms before the surgery, as well as depression and traumatic stress symptoms after a lower limb amputation, and the promotion of social support over time, in order to promote psychosocial adjustment to amputation. This set of psychosocial variables should be included when planning postamputation rehabilitation and psychosocial intervention programs for this target population.

\section{Impact and Implications}

The psychosocial adjustment to a lower limb amputation (LLA) is a complex interplay between psychological, individual, and environmental variables (Desmond \& Gallagher, 2008). Livneh's model of psychosocial adaptation to chronic illness and disability is a suitable theoretical framework to guide psychosocial interventions. The findings suggest a set of variables which should be considered when planning, pre- and postamputation rehabilitation programs and psychosocial interventions with this population. The findings support the need for an early assessment and treatment of pre- and postsurgery anxiety, given the association with social adjustment to LLA and traumatic stress symptoms 1 month after surgery. Anxiety symptoms and pre- and postsurgery level of functionality are important to psychosocial adjustment 10 months after LLA. Social support was a key mediating factor in psychosocial adjustment and should also be promoted in formal (hospital) and informal (community) settings. Given the small number of studies addressing the process of psychosocial adjustment to LLA in Portugal, further research is necessary before substantial conclusions may be reached.

Keywords: psychological reactions, functionality, social support, psychosocial adjustment, amputation
Susana Pedras, School of Psychology, University of Minho; Estela Vilhena, Technology School, 2Ai - Polytechnic Institute of Cávado and Ave and EPIUnit-ISPUP, University of Porto; Rui Carvalho, Multidisciplinary Diabetic Foot Clinic, Division of Endocrinology, Diabetes and Metabolism, Centro Hospitalar do Porto, Porto, Portugal; M. Graça Pereira, School of Psychology, University of Minho.

This study was conducted at the Psychology Research Center (PSI/ 01662), University of Minho, and supported by the Portuguese Ministry of Science, Technology and Higher Education through national funds and cofinanced by FEDER through COMPETE2020 under the PT2020 Partnership Agreement (POCI-01-0145-FEDER-007653) and by a grant (SFRH/BD/87704/2012) from the Portuguese Foundation for Science and Technology. The authors gratefully acknowledge the contributions of the Multidisciplinary Diabetic Foot Clinics of the following hospitals: CHP, CHSJ, CHVNG/E, CHTS, ULSAM, and the Vascular Surgery Departments in Braga and CHSJ Hospitals. The authors also wish to thank all patients who agreed to participate in this study.

Correspondence concerning this article should be addressed to Susana Pedras, PhD, School of Psychology, University of Minho, Campus Gualtar, 4710-057 Braga, Portugal. E-mail: susanapedras@ gmail.com 


\section{Introduction}

Portugal has the highest rate of diabetes mellitus (DM) in the European Union (EU), according to the Organization for Economic Cooperation and Development (OECD/EU, 2016). The data on the DM prevalence among adults in EU countries revealed that $7 \%$ of adults across countries, in 2014, reported having DM, ranging from 5\% in Sweden and Austria to over 9\%, in Greece, Portugal, and France (OECD/EU, 2016). There was an increasing trend in DM incidence in the past years in Portugal, making it a major public health problem. Several reasons explain this trend: the increase in the prevalence of obesity, elderly population, and changes in DM diagnosis criteria (de Sousa-Uva et al., 2016). As a result, approximately $13 \%$ of the Portuguese population have diabetes mellitus Type II (DMT2), and in 2015 Diabetic Foot Ulcers (DFUs) were responsible for 1,250 Lower Limb Amputations (LLA; 545 major and 705 minor; Portuguese Society of Diabetes [PSD], 2016). DFU is the term used to describe lesions in a patient's foot characterized by infection, ulceration, tissue destruction with neurologic abnormalities, peripheral arterial disease (PAD), and metabolic complications (Frykberg et al., 2000). DFU represents the major cause of LLA from a nontraumatic cause (Armstrong et al., 2001). In addition, these patients are first submitted to minor amputations (toes and transmetatarsal) but, five years after the first amputation, more than $50 \%$ of patients will already have suffered an amputation in the contralateral limb (Apelqvist \& Larsson, 2000), or a major amputation (above and below knee) in the same limb. This scenario makes DFU a costly complication of DM, both in terms of impact to the patient and in costs to national health systems (Anichini et al., 2007; Armstrong et al., 2001). In Portugal, DFU healing, major LLA, and death rates were equal to the rest of the European countries (Monteiro-Soares \& Dinis-Ribeiro, 2014) that collaborate in the Eurodiale study (Akhtar, Schaper, Apelqvist, \& Jude, 2011). However, patients with an active DFU were older and had deeper and more severe DFUs commonly located in the toes (Monteiro-Soares \& DinisRibeiro, 2014).

In Portugal little attention has been given to the psychological impact of DFU (Ferreira et al., 2014; Horta et al., 2003; MachadoVaz, Roque, Pimentel, Rocha, \& Duro, 2012) and subsequent LLA, although there are some studies that have addressed DFU from a clinical point of view without addressing the patient's psychosocial adjustment (Dias, 2006; Horta et al., 2003; Leão, Abreu, Padrão, \& Lemos, 1995; Machado-Vaz et al., 2012; Quadros, 2010; Ramos, 2011; Senra, 2013; Senra, Oliveira, Leal, \& Vieira, 2012). Nevertheless, to our knowledge, no portuguese study has focused on the psychosocial adjustment to LLA over time.

Psychological adjustment to LLA is vital, since patients need to manage not only their new physical condition and consequent psychological sequelae, but also the chronic disease underlying the amputation (in this case, DMT2; Iraj, Khorvash, Ebneshahidi, \& Askari, 2013). Thus, psychosocial adaptation to chronic illness and disability may be perceived and understood as the process of responding to the psychological, physical, social, and environmental changes that occur following a diagnosis of a chronic illness or an event that causes disability, such as LLA (Bishop, 2005; Livneh, 1986, 2001; Livneh \& Antonak, 1997, 1999).
Usually, the adjustment to LLA is measured and conceptualized as the absence of psychological symptoms. However, in this study, the conceptualization of the adjustment process to LLA is based on the complex and dynamic adaptation over time where the presence of psychological symptoms does not always mean a "poor" adjustment; rather, an effort to deal with the adversities and difficulties caused by a new physical condition (Coffey, Gallagher, Desmond, Ryall, \& Wegener, 2014). Nonetheless, in order to avoid the chronicity of psychological symptoms, it is essential to recognize their importance, and adequately assess and intervene accordingly.

The disability caused by a LLA, and the complexity of the adjustment process to amputation, have specificities and particularities that a generic measure of quality of life does not have sufficient sensitivity to detect (Gallagher \& MacLachlan, 2000a). Therefore, in this study, a specific measure of psychosocial adjustment for amputation was used. In addition to the need for adjustment to physical transformation, patients must adjust to social and psychological changes after LLA. Despite the contributions made by other assessment tools in this field, their focus has been especially on assessing physical factors such as general disability, adjustment to a prosthetic limb, and activity restriction measures (Rybarczyk, Nyenhuis, Nicholas, Cash, \& Kaiser, 1995; Williamson, 1995), and little or no attention has been given to psychosocial factors. Therefore, the Trinity Amputation and Prosthesis Experience Scales Revised (TAPES R) provides a brief and comprehensive assessment of the subjective experience of adjusting to a LLA. Gallagher and MacLachlan (2004), and recently Sinha, van den Heuvel, and Arokiasamy (2014), reported that TAPES was an adequate instrument to evaluate quality of life in this population. We believed that the process of adjustment to LLA is multifaceted and involves physical, psychological, and social demands that, in turn, may affect the overall quality of life, but this goal is beyond the scope of this study.

International studies found negative and positive predictors of psychosocial adjustment to LLA, particularly in terms of functionality and mobility, since these are the most objectively observable dimensions after LLA (Gallagher, O’Donovan, Doyle, \& Desmond, 2011; Leung, Wong, Wu, \& Guerin, 2004; Traballesi et al., 1998; Traballesi, Paolucci, Lubich, Pratesi, \& Brunelli, 1995; Wan Hazmy, Chia, Fong, \& Ganendra, 2006). In addition, the psychological reactions that influence the process of psychosocial adjustment to LLA short-, medium-, and long term are fundamental to deepen the understanding of this complex and dynamic process. On top of depression and anxiety symptoms, traumatic stress symptoms have also been reported in the literature (Copuroglu et al., 2010; Desmond \& MacLachlan, 2006a; Hawamdeh, Othman, \& Ibrahim, 2008; Machado-Vaz et al., 2012). Depression symptoms are common postsurgery symptoms (Coffey, Gallagher, Horgan, Desmond, \& MacLachlan, 2009; Desmond \& MacLachlan, 2006a; Livneh, Antonak, \& Gerhardt, 1999; Schoppen et al., 2003) that tend to decrease over time (Singh, Hunter, \& Philip, 2007). In a qualitative Portuguese study, symptoms such as sadness, depressive humor, and sleep disorders were reported by patients who had been submitted to LLA (Senra et al., 2012). Regarding anxiety symptoms, patients reported mainly anger and irritability (Senra et al., 2012) that were less prevalent than depression symptoms and, particularly present at postsurgery, but decreasing over time (Coffey et al., 2009; Desmond \& MacLachlan, 2006a; Hawamdeh et 
al., 2008; Horgan \& MacLachlan, 2004; Machado-Vaz et al., 2012).

Few studies have reported the presence of traumatic stress symptoms as a possible reaction after a LLA due to chronic illness (Cavanagh, Shin, Karamouz, \& Rauch, 2006; de Godoy, Braile, Buzatto, Longo, \& Fontes, 2002; Martz \& Cook, 2001; Phelps, Williams, Raichle, Turner, \& Ehde, 2008). Traumatic symptoms include reexperiencing the traumatic event (e.g., having nightmares or flashbacks), avoidance (e.g., feeling upset in response to reminders, wanting to avoid places related to the trauma), and hyperarousal (e.g., exaggerated startle response, hypervigilance, and difficulty sleeping). The presence of traumatic stress symptoms after LLA has never been studied, although observed in patients with several other diseases and/or undergoing physical and surgical procedures such as cancer (Pereira, Figueiredo, \& Fincham, 2012), cardiovascular disease (Coughlin, 2011), after an acute myocardial infarction (Wiedemar et al., 2008), HIV/AIDS (Rzeszutek, Oniszczenko, \& Firlag-Burkacka, 2012; Rzeszutek, Oniszczenko, Schier, Biernat-Kałuża, \& Gasik, 2016), in patients with chronic pain (Rzeszutek, Oniszczenko, Schier, Biernat-Kałuża \& Gasik, 2015; Rzeszutek et al., 2016), after a brain injury (Bryant, Moulds, Guthrie, \& Nixon, 2003), as well as after surgical procedures such as heart transplantation (Favaro et al., 2011) and cardioverter defibrillator implantation (Habibović, van den Broek, Alings, Van der Voort, \& Denollet, 2012). Therefore, the understanding of how traumatic stress symptoms affect psychosocial adjustment after a surgical procedure such as LLA is limited and has been largely overlooked.

Social support is seen as an environmental variable (or external factor) that contributes to chronic illness adjustment and acts as a buffer against negative and adverse experiences in a wide range of chronic diseases, including DMT2 (Schokker et al., 2010; Trief, Grant, Elbert, \& Weinstock, 1998) and after a LLA (Desmond \& Gallagher, 2008; Desmond \& MacLachlan, 2006b; Rybarczyk et al., 1992; Schoppen et al., 2003; Williams et al., 2004). However, studies of social support as a buffer against traumatic stress symptoms have yielded mixed results. In fact, some studies have reported a negative association between social support and traumatic stress but others have failed to do so (Hobfoll \& London, 1986; Springer \& Padgett, 2000).

Patients' coping strategies also play an important role in the process of psychosocial adjustment to LLA (Livneh \& Antonak, 1999; Livneh, Antonak, \& Gerhardt, 2000; Livneh \& Wilson, 2003), particularly problem-focused strategies that are associated with a positive adjustment (Desmond, 2007; Desmond \& MacLachlan, 2006b; Dunn, 1996; Gallagher \& MacLachlan, 1999; Livneh \& Antonak, 1999; Rybarczyk, Nicholas, \& Nyenhuis, 1997), greater functionality (Fusetti, Sénéchaud, \& Merlini, 2001; Gallagher \& MacLachlan, 2000b), and are negatively associated with depression (Livneh et al., 2000).

Therefore, given the paucity of studies that explore the psychosocial adjustment to LLA over time, and taking into account the psychological reactions, individual and environmental variables, this study, based on Livneh's (2001) theoretical framework, intends to fill the gap in this field. Livneh's theoretical framework advocates that adjustment to chronic illness and disability (CID) is a dynamic, continuous, and long-term process composed of three phases of adaptation and adjustment. In the first phase, antecedents and triggered events (presence of DMT2, DFU) as well as contextual variables (demographic variables and level of functional- ity) are taken into account. The second phase of the adjustment process contemplates the psychological reactions to CID (anxiety, depression, and traumatic stress symptoms), and the individual and environmental influences (social support and coping strategies). In the third phase of the model, the final rehabilitation goal for patients with CID, and the main outcome of this study, is the psychosocial adjustment to LLA.

Specifically, this study aims to (a) explore the role of pre- and postsurgery psychological reactions on psychosocial adjustment to LLA; (b) explore the mediator role of coping strategies and social support between psychological reactions and psychosocial adjustment to LLA; and finally, (c) examine how the psychological reactions and functionality influence psychosocial adjustment to LLA 10 months after surgery, controlling for gender and age as variables of interest, using a path analysis. We expect that: (a) presurgery psychological reactions (anxiety and depression symptoms) and postsurgery symptomatology (anxiety, depression, and traumatic stress symptoms) and level of functionality will be negatively associated with psychosocial adjustment, 10 months after LLA; and that (b) high social support and use of coping strategies will play a mediating role between psychological reactions, 1 month after surgery, and psychosocial adjustment, 10 months after LLA.

\section{Method}

\section{Participants}

A prospective cohort design was used where participants completed questionnaires on admission to LLA ( $\mathrm{t} 0), 1$ month after surgery (t1), 6 months (t2), and 10 months after LLA (t3). The follow-up was defined according to clinical criteria. Thus, of the 239 referred patients, 206 were included in the baseline assessment. Diabetic patients who did not undergo an amputation were excluded from the study after t0 $(n=62)$ and therefore, 144 patients participated at $\mathrm{t} 1$. Of these, only 107 participated at $\mathrm{t} 2$, and 96 participated 10 months after surgery, at t3. However, only 86 participated consecutively in all evaluations from to to $\mathrm{t} 3$. Several random and nonrandom reasons for nonparticipation were identified over time: refusal to participate, cognitive impairment after surgery, cancelled surgeries, patient's transferal to a different hospital, death, losses during follow-up consultation, and losses due to schedule mismatches. When compared, participants who dropped out after t0 did not differ significantly from those who remained in the study in their sociodemographic and clinical characteristics, with the exception of the ulcer duration $\left(t_{(204)}=\right.$ $.348 ; p \leq .05)$ and history of previous amputation $\left(\mathrm{X}^{2}=.239 ; p \leq\right.$ $.05)$, indicating that participants who withdrew were more likely to have a higher ulcer duration and having already been amputated.

\section{Measures}

Antecedents and contextual variables. Sociodemographic variables (age, gender, educational level, marital and professional status), diabetes-specific data (duration of DMT2, history of previous ulcers, ulcer duration, type of foot, and number of diabetesrelated complications), and amputation-specific information (level of previous amputation in patients already amputated but indicated for other amputation, and level of index amputation) were recorded 
at t0. Major amputation was defined as below and above-knee amputations, and minor amputations as toes and transmetatarsal, following the same categorization as previous studies (Moxey et al., 2011). The measures that patients completed at each assessment time are presented below.

The Barthel Index (BI, Araújo, Pais-Ribeiro, Oliveira, \& Pinto, 2007; Mahoney \& Barthel, 1965) is a scale that assesses the level of functionality for activities of daily living (ADLs) and comprises 10 items. Higher scores indicate higher levels. Cronbach's alpha was 0.87 .

Psychological responses.

Hospital Anxiety and Depression Scale (HADS, Pais-Ribeiro et al., 2007; Zigmond \& Snaith, 1983). This scale assesses depression (HADS-D) and anxiety symptoms (HADS-A) on a 14-item total scale, with seven items for each subscale. Higher scores indicate higher levels of anxiety and depressive symptoms. In this study, Cronbach's alpha for HADS-D was 0.88 and 0.86 for HADS-A.

Impact of Event Scale Revised (IES-R, Pereira et al., 2012; Pereira \& Pedras, 2016; Weiss \& Marmar, 1997). This scale assesses traumatic stress symptoms after a potentially traumatic event through 21 items grouped into three clusters of symptoms: reexperiencing, avoidance, and hyperarousal. Higher scores indicate higher number of traumatic stress symptoms. In this study, Cronbach's alpha was 0.94 .

Individual and environmental influences as mediators.

Satisfaction with Social Support Scale (SSSS, Pais-Ribeiro, 1999). This scale assesses satisfaction with social support and includes 15 items. A higher result indicates higher satisfaction with social support. The Cronbach's alpha in this study was 0.92 .

Ways of Coping Questionnaire (WOC, Folkman \& Lazarus, 1988; Pais-Ribeiro \& Santos, 2001). This scale assesses problem-focused (WOC-P) and emotion-focused coping strategies (WOC-E) and comprises a 48 items. Higher scores in each dimension indicate a higher use of the corresponding coping strategies. In this study, Cronbach's alpha was 0.90 and 0.77 for each dimension, respectively.

\section{Outcomes.}

Trinity Amputation and Prosthesis Experience Scales Revised (TAPES-R), Limb Loss version (Gallagher, Franchignoni, Giordano, \& MacLachlan, 2010; Pereira, Vilhena, \& Pedras, 2016). The first version of this instrument, TAPES (Trinity Amputation and Prosthesis Experience Scales), consisted of a multidimensional self-report instrument to better understand the experience of amputation and adjustment to a lower limb prosthesis (Gallagher \& MacLachlan, 2000a). The variability in individual's adjustment to LLA required a method and a tool to evaluate the level of adjustment to an artificial limb. Recently, a revised version was developed (Gallagher et al., 2010) presenting a simplified general structure and scores interpretation, that showed a high internal reliability and validity. A version for amputees with no prosthesis is also available. Several studies have already used TAPES-R to assess amputees with a prosthesis, but the present study is the first to use the TAPES-R version for amputees without prosthesis, due to the sample characteristics: patients with minor amputations and no eligibility criteria to use a prosthesis. The questionnaire includes three psychosocial subscales with five items each that measure general adjustment (GA), social adjustment (SA), and adjustment to the limitations (AL), with higher scores indicating better adjustment in each scale. Cronbach's alphas were 0.92 for GA, 0.96 for SA, and 0.94 for AL.

\section{Procedure}

Participants were recruited from six major hospitals in the North of Portugal providing specialized Diabetic Foot and Rehabilitation Clinical Care. The inclusion criteria were: having DMT2 and DFU, being indicated for a LLA amputation surgery, and being more than 18 years old. Exclusion criteria included a diagnosis of dementia or a psychiatric disorder recorded in the patient's medical records. Approval was granted from the ethical committees of all hospitals and all participants were informed about the purpose of the study prior to participation. Health professionals identified patients eligible to participate in the study, who voluntarily accepted and signed an informed consent form.

\section{Statistical Analysis}

Descriptive statistics were used to describe the sociodemographic and clinical characteristics of the sample. Furthermore, $t$ tests (for continuous variables) and chi-square tests (for nominal variables) were performed to compare demographic, clinical, and psychological measures between participants and the dropouts. These analyses were performed using the SPSS v.22.0 software.

In order to evaluate the impact of gender (male: 1 and female: 1 ) and age, depression, anxiety and traumatic stress symptoms, functionality, social support, and coping strategies in psychosocial adjustment to the LLA, three path analysis models were performed in order to explore the relationships of pre- and postsurgery variables and GA, SA, and AL. Path analysis uses bivariate and multiple linear regression techniques to test causal relations among variables and determine to what extent an independent variable directly and indirectly affects the dependent variable. The coefficients were computed through a series of multiple regression analyses (Olobatuyi, 2006).

Continuous variables were analyzed for a significant departure from normality. The robust maximum likelihood estimation procedure was used to account for the nonnormality of the data (Satorra \& Bentler, 1994). The adequacy of the model was assessed according to the goodness-of-fit indexes. The SatorraBentler Scale chi-square test was used. A nonsignificant $p$ value $(p>.05)$ and the ratio $\left(S-B \chi^{2}\right) / d f<3$ represent a good model fit. As the significance of a chi-square test is dependent on the number of participants, other goodness-of-fit indexes were also used. Comparative Fit Index (CFI) reaches a maximum value of 1.00 (derived from the comparison of the hypothesized model with the independent model), with values above 0.90 suggesting a good fit. Root Mean Square Error Approximation (RMSEA) was also used, where less than .05 indicates a good fit, but values up to 0.08 are considered acceptable (Hu \& Bentler, 1999).

Based on multivariate Lagrange Multiplier (LM) tests, post hoc modifications to the proposed model were made to add new paths as necessary. The significance of all direct and indirect effects was evaluated to determine which variables had a direct and indirect impact on psychosocial adjustment. The $R^{2}$ value was calculated for all predictors, mediators, and outcome variables to determine the proportion of variance explained on the outcome variable (Kline, 2011). Initially, the model included demographic variables 
to control for age and gender, but since age was not statistically significant it was removed. Additionally, the first theoretical model aimed to evaluate the simultaneous impact and the mediated effect of coping strategies on the outcome variables. As no statistically significant relationship was found between coping strategies and the psychosocial adjustment to LLA, a new model was tested, in which social support was tested as a mediator. The model only included variables associated with outcomes. Analyses were conducted with the EQS 6.1 package (Bentler, 2006), considering a 0.05 level of significance.

\section{Results}

\section{Sample Characteristics}

The sample comprised 86 patients that consecutively participated in all assessments from t0 to $\mathrm{t} 3$. The sample's sociodemographic and clinical characteristics at t0 are summarized in Table 1 and the descriptive statistics and correlations between pre- and postsurgery variables with psychosocial adjustment, 10 months after LLA, are summarized in Table 2.

\section{Path Analysis}

Path analysis yields two types of results: estimates of the model's fit to the data, and estimates of the strength of relationships between variables in the model. Results showed a good model fit: Model A-GA: $S-B \chi^{2}=13.81, p=.18 ; \frac{S-B_{\chi_{10}^{2}}}{d f}=1.381 ; \mathrm{CFI}=$ 0.98 ; RMSEA $=0.067(90 \%$ CI $[0.00 ; 0.14])$; Model B-AL: $S-B \chi^{2}=13.99, p=.12 ; \frac{S-B_{\chi_{9}^{2}}}{d f}=1.55 ; \mathrm{CFI}=0.98 ;$ RMSEA $=$

Table 1

Sample Sociodemographic and Clinical Characteristics at to $(n=86)$

\begin{tabular}{|c|c|c|c|c|}
\hline Continous measures & Min & $\operatorname{Max}$ & Mean & $S D$ \\
\hline Age & 36 & 90 & 63.23 & 10.84 \\
\hline Education level (years) & 0 & 17 & 5.13 & 3.40 \\
\hline DMT2 duration (months) & 1 & 636 & 208.4 & 141.86 \\
\hline History of previous ulcer (months) & 1 & 240 & 45.78 & 57.79 \\
\hline Ulcer duration (weeks) & 1 & 96 & 17.98 & 19.70 \\
\hline Number of complications & 1 & 4 & 3.03 & 1.01 \\
\hline Categorical measures & & & $n$ & $\%$ \\
\hline Gender (male) & & & 63 & 73.3 \\
\hline Professional Status (retired) & & & 58 & 67.4 \\
\hline Marital Status (married or cohabitant) & & & 60 & 69.8 \\
\hline Type of foot (neuroischemic) & & & 63 & 73.3 \\
\hline First amputation (yes) & & & 43 & 50.0 \\
\hline Previous amputation level (minor) & & & 33 & 76.7 \\
\hline Toes & & & 26 & 60.5 \\
\hline Transmetatarsal & & & 7 & 16.3 \\
\hline Below knee & & & 8 & 18.6 \\
\hline Above knee & & & 2 & 4.7 \\
\hline Index amputation level (minor) & & & 70 & 81.4 \\
\hline Toes & & & 66 & 76.7 \\
\hline Transmetatarsal & & & 5 & 5.8 \\
\hline Below knee & & & 9 & 10.5 \\
\hline Above knee & & & 6 & 7.0 \\
\hline
\end{tabular}

0.081 (90\% CI $[0.00 ; 0.16])$ and Model C-SA: $S-B \chi^{2}=13.81$, $p=.18 ; \frac{S-B_{\chi_{10}^{2}}}{d f}=1.381 ; \mathrm{CFI}=0.98 ; \mathrm{RMSEA}=0.067(90 \% \mathrm{CI}$ $[0.00 ; 0.144])$.

Regarding the outcome variables, results showed that, when simultaneously, including all variables in the model, traumatic stress symptoms ( $\mathrm{t} 1)$ were negatively associated with GA (b = $-0.267)$, AL $(b=-0.322)$, and SA $(b=-0.215) 10$ months after LLA. In all models, gender had a simultaneous and positive impact on anxiety at $\mathrm{t} 0(\mathrm{~b}=0.361 ; \mathrm{b}=0.325 ; \mathrm{b}=0.325$, for Model $\mathrm{A}$, $\mathrm{B}$, and $\mathrm{C}$ respectively) and on depression at $\mathrm{t} 0(\mathrm{~b}=0.370$, for Model $\mathrm{A}, \mathrm{B}$, and $\mathrm{C}$ respectively), and a negative impact on functionality at $\mathrm{t} 0(\mathrm{~b}=-0.275$, for Model $\mathrm{A}, \mathrm{B}$, and $\mathrm{C}$ respectively). In Model $\mathrm{C}$ gender was positively associated to functionality at $\mathrm{t} 0(\mathrm{~b}=-0.275)$. Functionality at t0 $(\mathrm{b}=0.238)$ and social support at $\mathrm{t} 2(\mathrm{~b}=0.321)$ had also a simultaneous and significant impact on the AL. Anxiety at t0 $(b=-0.218)$ had a negative impact on SA.

In all models, taking into account the contribution of presurgery variables, depression symptoms at t0 were significantly associated with depression at $\mathrm{t} 1(\mathrm{~b}=0.391 ; \mathrm{b}=0.385 ; \mathrm{b}=0.391$, for Model $\mathrm{A}, \mathrm{B}$, and $\mathrm{C}$ respectively) and with anxiety symptoms at $\mathrm{t} 1 \mathrm{(b}=$ $0.215 ; b=0.207 ; b=0.215$, for Model $A, B$, and $C$ respectively), and anxiety symptoms at $\mathrm{t} 0$ contribute to anxiety at $\mathrm{t} 1(\mathrm{~b}=0.357$; $\mathrm{b}=0.357 ; \mathrm{b}=0.351$, for Model $\mathrm{A}, \mathrm{B}$, and $\mathrm{C}$ respectively). Functionality at $\mathrm{t} 0$ was associated with functionality at $\mathrm{t} 1$ in all models $(b=0.561)$. Anxiety $(b=-0.391)$ and traumatic symptoms $(b=0.248)$, at $t 1$, were negatively and positively related to social support at $\mathrm{t} 2$, respectively (Figures 1, 2, and 3).

Mediation analyses were assessed by analyzing the significance of the indirect effect between predictors and adjustment components (Preacher \& Kelley, 2011). Results showed a statistically significant indirect effect of social support, i.e. social support at $\mathrm{t} 2$ partially mediated the relationship between traumatic stress symptoms at $\mathrm{t} 1$ and $\mathrm{AL}$ at $\mathrm{t} 3$, in Model B (see Figure 2).

\section{Discussion}

In view of the increased incidence of DM in Portugal, it is expected that the number of patients with DFU and consequent LLA will increase, making it vital to study the process of psychosocial adjustment to LLA in patients amputated due to DM. Thus, this study intended to fill the gap in the process of psychosocial adjustment to LLA over time, taking into account patients " psychological reactions, individual and environmental variables, controlling for age and gender, based on Livneh's (2001) theoretical framework. Thus, this study adds to literature knowledge on the association of gender, level of pre- and postsurgery functionality level, and pre- and postsurgery psychological reactions in the psychosocial adjustment to LLA 10 months after surgery, as well as the mediating role of social support between psychological reactions and adjustment to limitations.

Regarding the influence of the presurgery variables, psychological reactions before surgery (anxiety and depression symptoms) were predictors of postsurgery psychological reactions, as has been reported in other studies (Caumo et al., 2001; Karanci \& Dirik, 2003; Pinto, McIntyre, Ferrero, Almeida, \& Araújo-Soares, 2013), reinforcing the need of assessment and intervention before the amputation surgery. However, psycho- 
Table 2

Correlation Between Pre- and Postsurgery Variables and Psychosocial Adjustment 10 Months After LLA

\begin{tabular}{|c|c|c|c|c|c|c|c|c|c|c|c|}
\hline Variables & 1 & 2 & 3 & 4 & 5 & 6 & 7 & 8 & 9 & 10 & 11 \\
\hline 1. HADS_A (t0) & 1 & $.43^{\dagger}$ & $.38^{\dagger}$ & $.33^{\dagger}$ & $-.17^{*}$ & -.11 & $-.29^{\dagger}$ & -.08 & $-.26^{*}$ & $-.29^{\dagger}$ & .15 \\
\hline 2. HADS A (t1) & & 1 & $.34^{\dagger}$ & $.58^{\dagger}$ & -.10 & $-.35^{\dagger}$ & $.45^{\dagger}$ & $-.35^{\dagger}$ & $.28^{*}$ & $-.21^{*}$ & $.21^{*}$ \\
\hline 3. HADS_D (t0) & & & 1 & $.46^{\dagger}$ & $-.46^{\dagger}$ & $-.42^{\dagger}$ & $.21^{\dagger}$ & $-.42^{\dagger}$ & $-.38^{\dagger}$ & $-.30^{\dagger}$ & $.41^{\dagger}$ \\
\hline 4. HADS_D (t1) & & & & 1 & $-.30^{\dagger}$ & $-.42^{\dagger}$ & $-.31^{\dagger}$ & $-.23^{*}$ & $-.30^{\dagger}$ & $-.31^{\dagger}$ & $.32^{\dagger}$ \\
\hline 5. $\mathrm{BI}(\mathrm{t} 0)$ & & & & & 1 & $.55^{\dagger}$ & -.17 & $.23^{*}$ & $.21^{*}$ & .09 & $-.43^{\dagger}$ \\
\hline 6. BI (t1) & & & & & & 1 & -.14 & $.30^{\dagger}$ & $.28^{\dagger}$ & .18 & $-.43^{\dagger}$ \\
\hline 7. IES (t1) & & & & & & & 1 & -.01 & $-.33^{\dagger}$ & $-.28^{\dagger}$ & $-.30^{\dagger}$ \\
\hline 8. SSSS (t2) & & & & & & & & 1 & .16 & .14 & $-.34^{\dagger}$ \\
\hline 9. GA (t3) & & & & & & & & & 1 & $.67^{\dagger}$ & $-.60^{\dagger}$ \\
\hline 10. SA (t3) & & & & & & & & & & 1 & $-.58^{\dagger}$ \\
\hline 11. AL (t3) & & & & & & & & & & & 1 \\
\hline
\end{tabular}

Note. $\quad$ HADS-A = Anxiety Scale; HADS-D = Depression Scale; BI = Barthel Index; IES-R = Impact of Event Scale Revised; SSSS = Satisfaction with Social Support Scale; $\mathrm{GA}=$ General Adjustment; $\mathrm{SA}=$ Social Adjustment; $\mathrm{AL}=$ Adjustment to Limitations; $\mathrm{t} 0=$ presurgery; $\mathrm{t} 1=1$ month after surgery; $\mathrm{t} 2=6$ months after surgery; $\mathrm{t} 3=10$ months after surgery.

${ }^{*} p<.05 .{ }^{\dagger} p<.01$.

logical evaluation and intervention are recommended, especially at presurgery, regarding the negative association between anxiety symptoms and social adjustment 10 months after LLA (Coffey et al., 2009).

Findings also indicated that traumatic stress symptoms 1 month after surgery were negatively associated with general and social adjustment, and adjustment to limitations, that is, in overall psychosocial adjustment to LLA 10 months after surgery. Few studies have focused on the traumatic reaction to amputation in this population (Cavanagh et al., 2006; de Godoy et al., 2002; Martz \& Cook, 2001; Phelps et al., 2008), based on the assumption that patients amputated due to a chronic disease are better prepared for this clinical outcome, especially since the amputation is not the result of an unpredictable or uncontrollable situation. However, this study revealed that this is not always the case, and steps must be taken to avoid not only the progression of traumatic stress symptoms, but also their negative effect on psychosocial adjustment 10 months after LLA. There is a growing body of evidence on the possibility that a life-threatening situation, such as a physical condition or a surgical procedure, may increase the likelihood of exhibiting symptoms of traumatic stress or even a Posttraumatic Stress Disorder (PTSD). (Bryant et al., 2003; Coughlin, 2011; Favaro et al., 2011; Habibović et al., 2012; Pereira et al., 2012; Rzeszutek et al., 2012, 2015, 2016; Wiedemar et al., 2008). Still, this issue should be better explored. In addition, regarding amputation due to a chronic disease, further research is needed to explore which clusters of symptoms have a greater impact on the adjustment to LLA, as well as to understand the trajectories of symptoms over time.

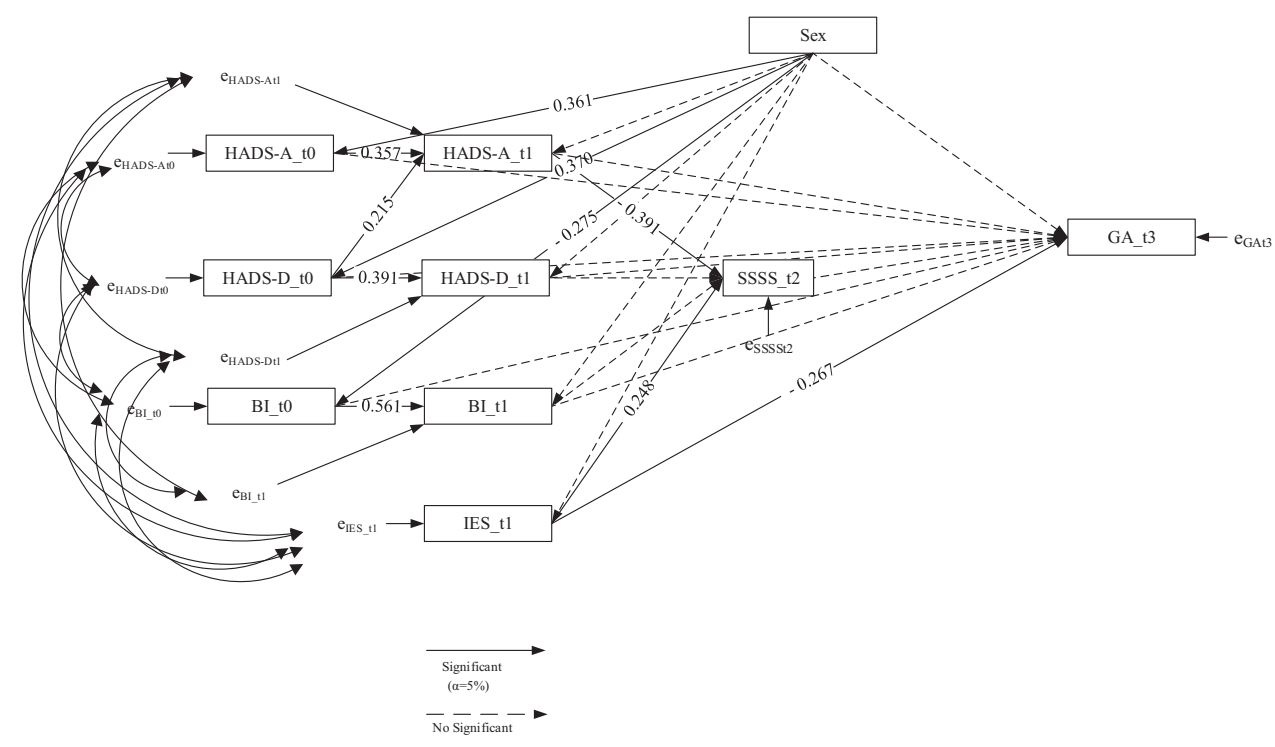

Figure 1. Standardized path coefficients for Model A: General Adjustment. Fit indices of Model A: $S-B \chi^{2}=$ $13.81, p=0.18, \mathrm{CFI}=0.98$, RMSEA $=0.07$. HADS-A = Anxiety Scale; HADS-D = Depression Scale; BI $=$ Barthel Index; IES-R = Impact of Event Scale Revised; SSSS = Satisfaction with Social Support Scale; $\mathrm{GA}=$ General Adjustment; $\mathrm{t} 0=$ presurgery; $\mathrm{t} 1=1$ month after surgery; $\mathrm{t} 2=6$ months after surgery; $\mathrm{t} 3=10$ months after surgery. 


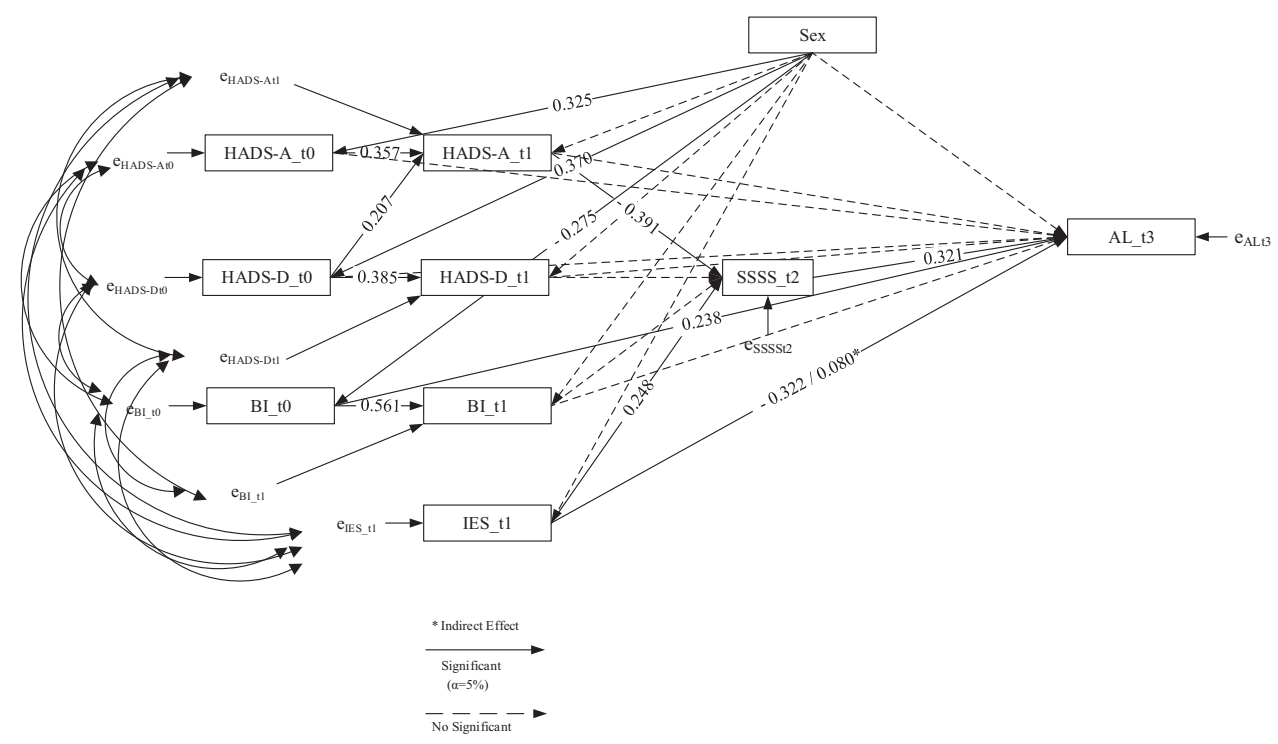

Figure 2. Standardized path coefficients for Model B: Adjustment to Limitations. Fit indices of Model B: $S-B \chi^{2}=13.99, p=0.12, \mathrm{CFI}=0.98, \mathrm{RMSEA}=0.08$. HADS-A $=$ Anxiety Scale; HADS-D $=$ Depression Scale; BI = Barthel Index; IES-R = Impact of Event Scale Revised; SSSS = Satisfaction with Social Support Scale; $\mathrm{AL}=$ Adjustment to Limitations; $\mathrm{t} 0=$ presurgery; $\mathrm{t} 1=1$ month after surgery; $\mathrm{t} 2=6$ months after surgery; $\mathrm{t} 3=10$ months after surgery.

Moreover, it is important to stress that unrecognized and unaddressed trauma symptoms may result in poor physical, mental, and social outcomes (Schneiderman, Ironson, \& Siegel, 2005). Given the variety of clinical phenotypes consistent with a PTSD diagnostic criteria, this disorder is no longer merely considered an anxiety disorder, but rather was relocated into a new category named "Trauma and Stressor-
Related Disorders," according to the Diagnostic and Statistical Manual of Mental Disorders (DSM-5; American Psychiatric Association [APA], 2013). Therefore, it is urgent to construct and validate new measures to evaluate traumatic stress symptoms, according to the four clusters of symptoms now reported in the new DSM-5 edition (APA, 2013).

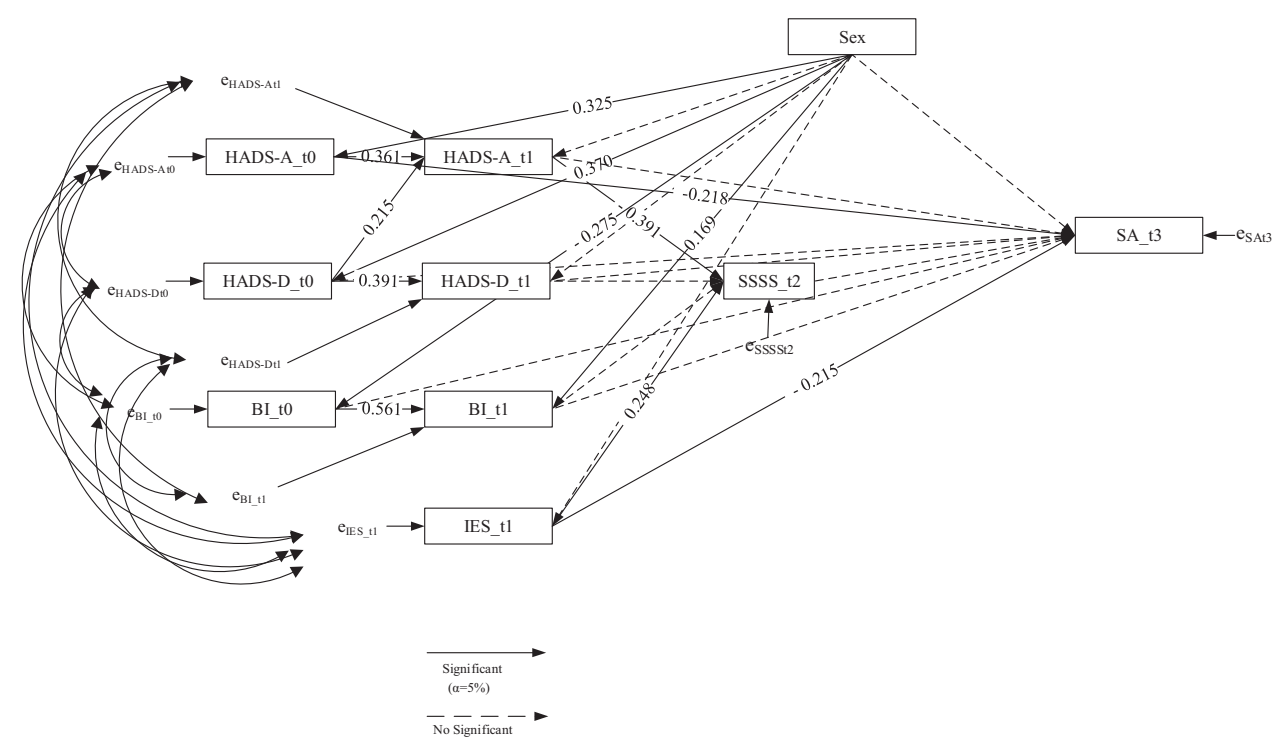

Figure 3. Standardized path coefficients for Model C: Social Adjustment. Fit indices of Model C: $S-B \chi^{2}=$ $13.81, p=0.18, \mathrm{CFI}=0.98, \mathrm{RMSEA}=0.07$. HADS-A $=$ Anxiety Scale; HADS-D $=$ Depression Scale; $\mathrm{BI}=$ Barthel Index; IES-R = Impact of Event Scale Revised; SSSS = Satisfaction with Social Support Scale; SA = Social Adjustment; $\mathrm{t} 0=$ presurgery; $\mathrm{t} 1=1$ month after surgery; $\mathrm{t} 2=6$ months after surgery; $\mathrm{t} 3=10$ months after surgery. 
As expected, a lower level of baseline functionality (ability to perform ADLs), in addition to being associated with the level of postoperative functionality, was also a predictor of adjustment to the limitations, 10 months after LLA. Anderson and colleagues (2017) also found a similar relationship, but between functionality and depressive symptoms, 12 months after LLA. Disability parameters and functional limitations have been considered risk factors for psychosocial adjustment to LLA (Desmond \& Gallagher, 2008). In addition, gender played a distinctive role regarding functionality, wherein male patients showed less presurgery functionality compared to women regarding adjustment to the limitations, general and social adjustment, but more postsurgery functionality, regarding adjustment to limitations. However, no differences were found in the psychosocial outcomes following LLA according to gender as other studies have also documented (Behel, Rybarczyk, Elliott, Nicholas, \& Nyenhuis, 2002; Gallagher \& MacLachlan, 2001; Rybarczyk et al., 1992), which may be explained by the lower number of women in the studies' samples. In addition, according to the results of the present study, male patients also reported more anxiety and depression symptoms in the preoperative period, affecting adjustment to limitations at $\mathrm{t} 3$, indicating that they may benefit more from intensive rehabilitation treatment and psychological support before the surgery.

Social support, 6 months after surgery, was a mediator in the relationship between traumatic stress symptoms 1 month after surgery and adjustment to limitations 10 months after LLA, emphasizing the need to promote social support in this population. The positive role of social support as a predictor and mediator between the emotional consequences of a chronic illness and diabetes outcomes (adherence to medication and self-care behaviors) is widely recognized, particularly in DMT2 (Pereira, Pedras, Machado, \& Ferreira, 2016; Schokker et al., 2010; Trief et al., 1998). However, after an LLA, there are few studies that describe the importance of social support in the process of adjustment to LLA and, especially, how to promote its use as a valuable resource (Desmond \& Gallagher, 2008; Desmond \& MacLachlan, 2006b; Horgan \& MacLachlan, 2004; Rybarczyk et al., 1992; Schoppen et al., 2003; Williams et al., 2004). In fact, in the study of Williams and collaborators, social support was only assessed 1 month after amputation, ranging from almost no support to a maximum amount of support, and predicted life satisfaction, mobility, and occupational functioning, 6 months after amputation. In this study, social support was only a mediator between traumatic stress symptoms and adjustment to limitations, but not between traumatic stress and social adjustment, as expected. In turn, coping strategies did not play a mediating role between emotional reactions and adjustment to the LLA. One may hypothesize that social support may have a greater impact on adjustment to the limitations than coping strategies during the first 10 months after surgery and, in the latter case, social support may act as a coping strategy. Future studies should test this hypothesis. Social support was a mediator between traumatic stress symptoms and adjustment to limitations, an intuitive result given that support from relatives and friends as well as from community may be more valuable and effective in adjusting to limitations after LLA than the presence of coping strategies. Also, Couture and collaborators (Couture, Caron, \& Desrosiers, 2010; Couture, Desrosiers, \& Caron, 2011) found that coping strategies were not significant in the period of rehabilitation (t2: 2 weeks), and that social support played an important role in adjustment during hospitalization (t1: 2 weeks) and after discharge (t3: 2 and 3 months after discharge from rehabilitation). Since the instrument used in this study to assess coping strategies has already been used in other similar studies (Fusetti et al., 2001; Gallagher \& MacLachlan, 2000b; van de Weg \& van der Windt, 2005) and has demonstrated adequate psychometric properties in this population, it is crucial to understand which coping strategies are most useful, when, and in which context since the effectiveness of coping strategies are directly related to the context in which they are used. Findings also revealed that patients with anxiety symptoms 1 month after surgery perceived having less available social support 6 months after surgery. In our view, patients with fewer anxiety symptoms may be more emotionally stable and feel closer to friends and family. Psychological distress may interfere with the patient's interaction with the social network resulting in a lower perception of available social support resources (Baek, Tanenbaum, \& Gonzalez, 2014; Han et al., 2014; Mollaoglu, 2006). It is important to emphasize that the instrument used in this study assesses satisfaction with the support provided by friends and relatives considered available support (e.g., "I'm satisfied with the kind of friends I have," "When I need to vent with someone I easily find friends with whom to do it," "I'm satisfied with the way I relate to my family"). Overall, the quality of relationships, the structure of social networks, and friends ' availability seem to be essential in LLA patients.

As we have already reported, studies of perceived social support where social support acts as a buffer against traumatic stress symptoms have yielded mixed results (Hobfoll \& London, 1986; Springer \& Padgett, 2000). If, on the one hand, perceived social support may be a buffer against the negative effects of traumatic stress symptoms, on the other hand, the latter may reduce social support, suggesting a bidirectional relationship. Patients with traumatic stress symptoms may report irritability, interpersonal difficulties, and feelings of detachment from others avoiding social contacts, which in turn may erode social relationships (Clapp \& Beck, 2009). According to the results, patients with more traumatic stress symptoms 1 month after surgery perceived a higher social support 6 months after surgery, which might be a good indicator of perceived available support, that, in turn, may help with the patient's adjustment since, after surgery, the demands for support will likely increase and patients will have to rely on others for the activities of daily living.

The findings of the present study highlight the role of functionality in presurgery and psychological reactions to LLA, at short-, medium-, and long term as well as the important role of anxiety symptoms in presurgery, traumatic stress symptoms 1 month after surgery, and perceived social support for the patient's psychosocial adjustment 10 months after LLA. Given that the predictors of psychosocial adjustment, except for gender, are susceptible to change, psychosocial interventions may be helpful, positively influencing the psychosocial adjustment to a LLA. Hence, psychosocial adjustment could be promoted by providing psychological support in dealing with anxiety and traumatic stress symptoms before and immediately after surgery in order to prevent the development of a Posttraumatic Stress Disorder. Cognitive behavior strategies have been the gold standard intervention in reducing anxiety and traumatic stress symptoms in patients with LLA (Srivastava \& Chaudhury, 2014; Wegener, Hofkamp, \& Ehde, 2008). As Horgan and MacLachlan (2004) stated, the initial 2 years 
following LLA are a period of great susceptibility to the development and maintenance of psychological symptoms affecting adjustment, but according to our results, the 1-year period after LLA is already an important time for intervention to take place. Moreover, the assessment of patients with LLA should use appropriately selected screening tools adapted to limb loss, such as TAPES-R (Gallagher et al., 2010), as well as specific measures to assess the presence of a Posttraumatic Stress Disorder, such as the ClinicianAdministered PTSD Scale (CAPS; Blake et al., 1995) and, consequently, a specific psychotherapeutic intervention.

In the present study, social support played an important role as a mediator in contrast to coping strategies. Thus, social support should be promoted by formal psychosocial interventions not only at the hospital during an inpatient stay, but also over time, integrating community resources, such as amputee support groups, daycare centers, and informal patient associations, given that LLA greater constraints will be perceived when patients return home. Also, intervention programs using volunteer peer mentors (individuals that have already experienced this situation) may be helpful in assisting patients during hospital admissions, as well as in the early phase of adjustment (Wegener et al., 2008). Other studies have shown that peer-based programs improve outcomes for patients with spinal cord injury and for their family members (Ljungberg, Kroll, Libin, \& Gordon, 2011). Additionally, patients with LLA often report limitations when participating in leisure activities, especially crafts, nature and outdoor activities, mechanics, sports, and physical activities due to lack of accessibility, functional abilities, and affective, financial, and social constraints (Couture et al., 2010). Therefore, formal interventions may be particularly valuable where informal support is lacking, by facilitating participation in activities and, consequently, helping to improve satisfaction with social support, promoting the adjustment to the limitations after a LLA.

The strengths of this study include the use of a specific measure to assess psychosocial adjustment instead of a quality-of-life measure (given that adjustment and quality of life are different constructs), the inclusion of patients recruited at six hospitals, and the three assessment follow-ups, making this study multicenter and longitudinal. Future studies should combine efforts to understand the course of coping strategies, which coping strategies influence adjustment over time, as well as to define what is "coping with LLA" for patients. In this study, coping strategies were not statistically significant predictors or mediators and were therefore removed from the model. However, coping may play an important role in the process of adjustment to LLA and future studies need to assess coping strategies at different times in the adjustment process. A growing body of research on positive psychosocial adjustment to amputation has been published (Couture et al., 2011; Dunn, 1996; Gallagher \& MacLachlan, 2000b; Oaksford, Frude, \& Cuddihy, 2005; Phelps et al., 2008; Rybarczyk et al., 1997) and should be further developed in order to deepen the knowledge regarding the "positive" psychological features (such as optimism) beyond the "negative" that are well known contributors to psychosocial adjustment after LLA. Continued efforts are required to increase the understanding of the impact of LLA on family functioning, the marital relationship, and informal caregivers.

In terms of implications for clinical practice, future studies should focus on the efficacy of psychosocial interventions with a strong evidence base. Psychosocial interventions should be pre- ventive, targeting the psychological responses, especially symptoms of anxiety, promoting as well the level of functionality before surgery, in order to prevent adverse psychological reactions after surgery and difficulties in the adjustment process. The promotion of social support with the aim of optimizing psychosocial adjustment to amputation, not only during hospitalization but also over time, should also be a target for intervention. Livneh's (2001) model seems to be an adequate theoretical framework to assist in the design of future interventions with this population. In addition, amputated patients' due to DFU who are not candidates for prosthetic rehabilitation may experience a different process of adjustment, as well as amputees who underwent a minor amputation (e.g., toes or transmetatarsal) but may be at risk of a major reamputation. For those patients at risk for a major reamputation, a more intensive psychological support may need to be provided, not only in order to promote psychosocial adjustment (general, social, and to limitations) to LLA, but also to promote adherence to foot self-care behaviors, adherence to an orthosis, crutches, or wheelchair use, promoting functionality and independent living. Rehabilitation goals for a minor amputation may be more modest but still as important as a major amputation.

The fact that data collection took place at six major hospitals located in the north of the country, but where the registered amputation rate is the lowest in the country (PSD, 2016) and where there is the greatest number of multidisciplinary diabetic foot units, may be considered simultaneously a strength and a limitation. In the future, it would be interesting to compare the results with data from other different geographical areas with higher amputation rates and fewer specialized diabetic foot care units.

It is important also to acknowledge some limitations in the present study. Consistent with previous studies in this population, the attrition rate was $58 \%$; that is, only this percentage of the original sample participated in the $\mathrm{t} 3$ assessment. Also, due to the sample size, the results should be cautiously interpreted and the path analysis models should be tested on bigger samples reducing Type II error estimates. In addition, the sample included a high percentage of patients who underwent a minor amputation (toes and transmetatarsal); thus, generalization of these findings to more traditional limb loss samples that include major limb amputations (above and below knee), with markedly different functional outcomes, should be carefully considered. Nonetheless, attention should also be given to patients with minor amputations, since they are at a higher risk of a long-term major amputation due to the effects of peripheral arterial disease.

\section{References}

Akhtar, S., Schaper, N., Apelqvist, J., \& Jude, E. (2011). A review of the Eurodiale studies: What lessons for diabetic foot care? Current Diabetes Reports, 11, 302-309. http://dx.doi.org/10.1007/s11892-011-0195-x

American Psychiatric Association (APA). (2013). Diagnostic and statistical manual of mental disorders (5th ed.). Washington, DC: Author.

Anderson, D. R., Roubinov, D. S., Turner, A. P., Williams, R. M., Norvell, D. C., \& Czerniecki, J. M. (2017). Perceived social support moderates the relationship between activities of daily living and depression after lower limb loss. Rehabilitation Psychology, 62, 214-220. http://dx.doi .org/10.1037/rep0000133

Anichini, R., Zecchini, F., Cerretini, I., Meucci, G., Fusilli, D., Alviggi, L., . . . De Bellis, A. (2007). Improvement of diabetic foot care after the implementation of the International Consensus on the Diabetic Foot 
(ICDF): Results of a 5-year prospective study. Diabetes Research and Clinical Practice, 75, 153-158. http://dx.doi.org/10.1016/j.diabres.2006 .05 .014

Apelqvist, J., \& Larsson, J. (2000). What is the most effective way to reduce incidence of amputation in the diabetic foot? Diabetes/ Metabolism Research and Reviews, 16(Suppl. 1), S75-S83. http://dx.doi .org/10.1002/1520-7560(200009/10)16:1+<::AID-DMRR139>3.0 . $\mathrm{CO} ; 2-8$

Araújo, F., Pais-Ribeiro, L., Oliveira, A., \& Pinto, C. (2007). Validação do Índice de Barthel numa amostra de idosos não institucionalizados [Validation of the Barthel Index in a sample of non-institutionalized elderly]. Revista Portuguesa de Saude Publica, 25, 59-66.

Armstrong, D. G., Nguyen, H. C., Lavery, L. A., van Schie, C. H., Boulton, A. J., \& Harkless, L. B. (2001). Off-loading the diabetic foot wound: A randomized clinical trial. Diabetes Care, 24, 1019-1022. http://dx.doi .org/10.2337/diacare.24.6.1019

Baek, R. N., Tanenbaum, M. L., \& Gonzalez, J. S. (2014). Diabetes burden and diabetes distress: The buffering effect of social support. Annals of Behavioral Medicine, 48, 145-155. http://dx.doi.org/10.1007/s12160013-9585-4

Behel, J. M., Rybarczyk, B., Elliott, T. R., Nicholas, J. J., \& Nyenhuis, D. (2002). The role of perceived vulnerability in adjustment to lower extremity amputation: A preliminary investigation. Rehabilitation Psychology, 47, 92-105. http://dx.doi.org/10.1037/0090-5550.47.1.92

Bentler, P. M. (2006). EQS 6 Structural Equations program manual. Encino, CA: Multivariate Software.

Bishop, M. (2005). Quality of life and psychosocial adaptation to chronic illness and disability. Rehabilitation Counseling Bulletin, 48, 219-231. http://dx.doi.org/10.1177/00343552050480040301

Blake, D. D., Weathers, F. W., Nagy, L. M., Kaloupek, D. G., Gusman, F. D., Charney, D. S., \& Keane, T. M. (1995). The development of a clinician-administered PTSD scale. Journal of Traumatic Stress, 8, 75-90. http://dx.doi.org/10.1002/jts.2490080106

Bryant, R. A., Moulds, M., Guthrie, R., \& Nixon, R. D. (2003). Treating acute stress disorder following mild traumatic brain injury. The American Journal of Psychiatry, 160, 585-587. http://dx.doi.org/10.1176/appi .ajp.160.3.585

Caumo, W., Schmidt, A. P., Schneider, C. N., Bergmann, J., Iwamoto, C. W., Adamatti, L. C., . . . Ferreira, M. B. (2001). Risk factors for postoperative anxiety in adults. Anaesthesia, 56, 720-728. http://dx.doi .org/10.1046/j.1365-2044.2001.01842.x

Cavanagh, S. R., Shin, L. M., Karamouz, N., \& Rauch, S. L. (2006). Psychiatric and emotional sequelae of surgical amputation. Psychosomatics, 47, 459-464. http://dx.doi.org/10.1176/appi.psy.47.6.459

Clapp, J. D., \& Beck, J. G. (2009). Understanding the relationship between PTSD and social support: The role of negative network orientation. Behaviour Research and Therapy, 47, 237-244. http://dx.doi.org/10 .1016/j.brat.2008.12.006

Coffey, L., Gallagher, P., Desmond, D., Ryall, N., \& Wegener, S. T. (2014). Goal management tendencies predict trajectories of adjustment to lower limb amputation up to 15 months post rehabilitation discharge. Archives of Physical Medicine and Rehabilitation, 95, 1895-1902. http://dx.doi.org/10.1016/j.apmr.2014.05.012

Coffey, L., Gallagher, P., Horgan, O., Desmond, D., \& MacLachlan, M. (2009). Psychosocial adjustment to diabetes-related lower limb amputation. Diabetic Medicine, 26, 1063-1067. http://dx.doi.org/10.1111/j .1464-5491.2009.02802.x

Copuroglu, C., Ozcan, M., Yilmaz, B., Gorgulu, Y., Abay, E., \& Yalniz, E. (2010). Acute stress disorder and post-traumatic stress disorder following traumatic amputation. Acta Orthopaedica Belgica, 76, 90-93.

Coughlin, S. S. (2011). Post-traumatic stress disorder and cardiovascular disease. The Open Cardiovascular Medicine Journal, 5, 164-170. http:// dx.doi.org/10.2174/1874192401105010164
Couture, M., Caron, C. D., \& Desrosiers, J. (2010). Leisure activities following a lower limb amputation. Disability and Rehabilitation, 32, 57-64. http://dx.doi.org/10.3109/09638280902998797

Couture, M., Desrosiers, J., \& Caron, C. D. (2011). Cognitive appraisal and perceived benefits of dysvascular lower limb amputation: A longitudinal study. Archives of Gerontology and Geriatrics, 52, 5-11. http://dx.doi .org/10.1016/j.archger.2009.11.002

de Godoy, J. M. P., Braile, D. M., Buzatto, S. H. G., Longo, O., \& Fontes, O. A. (2002). Quality of life after amputation. Psychology, Health \& Medicine, 7, 397-400. http://dx.doi.org/10.1080/135485002100 0015212

Desmond, D. M. (2007). Coping, affective distress, and psychosocial adjustment among people with traumatic upper limb amputations. Journal of Psychosomatic Research, 62, 15-21. http://dx.doi.org/10.1016/j .jpsychores.2006.07.027

Desmond, D., \& Gallagher, P. (2008). Coping and psychosocial adjustment to amputation. In P. Gallagher, D. Desmond, \& M. MacLachlan (Eds.), Psychoprosthetics: An introduction (pp. 11-21). London, UK: SpringerVerlag. http://dx.doi.org/10.1007/978-1-84628-980-4_2

Desmond, D. M., \& MacLachlan, M. (2006a). Affective distress and amputation-related pain among older men with long-term, traumatic limb amputations. Journal of Pain and Symptom Management, 31, 362-368. http://dx.doi.org/10.1016/j.jpainsymman.2005.08.014

Desmond, D. M., \& MacLachlan, M. (2006b). Coping strategies as predictors of psychosocial adaptation in a sample of elderly veterans with acquired lower limb amputations. Social Science \& Medicine, 62, 208 216. http://dx.doi.org/10.1016/j.socscimed.2005.05.011

de Sousa-Uva, M., Antunes, L., Nunes, B., Rodrigues, A. P., Simões, J. A., Ribeiro, R. T., . . Matias-Dias, C. (2016). Trends in diabetes incidence from 1992 to 2015 and projections for 2024: A Portuguese General Practitioner's Network study. Primary Care Diabetes, 10, 329-333. http://dx.doi.org/10.1016/j.pcd.2016.05.003

Dias, M. R. (2006). Qualidade de vida relacionada com a saúde e satisfação com a vida [Quality of life related to health and life satisfaction] (Master's thesis). Retrieved from http://hdl.handle.net/10216/97049

Dunn, D. S. (1996). Well-being following amputation: Salutary effects of positive meaning, optimism, and control. Rehabilitation Psychology, 41, 285-302. http://dx.doi.org/10.1037/0090-5550.41.4.285

Favaro, A., Gerosa, G., Caforio, A. L., Volpe, B., Rupolo, G., Zarneri, D., ... Santonastaso, P. (2011). Posttraumatic stress disorder and depression in heart transplantation recipients: The relationship with outcome and adherence to medical treatment. General Hospital Psychiatry, 33, 1-7. http://dx.doi.org/10.1016/j.genhosppsych.2010.10.001

Ferreira, V., Martins, J., Loureiro, L., Loureiro, T., Borges, L., Silveira, D., . . Almeida, R. (2014). Consulta multidisciplinar do pé diabético: Avaliação dos fatores de mau prognóstico [Multidisciplinary consultation of diabetic foot-Factors related with bad prognosis]. Angiologia e Cirurgia Vascular, 10, 146-150. http://dx.doi.org/10.1016/j.ancv.2014 .08 .005

Folkman, S., \& Lazarus, R. S. (1988). Manual for the Ways of Coping Questionnaire. Palo Alto, CA: Consulting Psychologists Press.

Frykberg, R. G., Armstrong, D. G., Giurini, J., Edwards, A., Kravette, M., Kravitz, S., . . Vanore, J. (2000). Diabetic foot disorders: A clinical practice guideline. The Journal of Foot and Ankle Surgery, 39(Suppl. 5), S1-S60.

Fusetti, C., Sénéchaud, C., \& Merlini, M. (2001). La qualité de vie des patients vasculaires amputés [Quality of life of vascular disease patients following amputation]. Annales de Chirurgie, 126, 434-439. http://dx .doi.org/10.1016/S0003-3944(01)00541-7

Gallagher, P., Franchignoni, F., Giordano, A., \& MacLachlan, M. (2010). Trinity Amputation and Prosthesis Experience Scales: A psychometric assessment using classical test theory and Rasch analysis. American Journal of Physical Medicine \& Rehabilitation, 89, 487-496. http://dx .doi.org/10.1097/PHM.0b013e3181dd8cf1 
Gallagher, P., \& MacLachlan, M. (1999). Psychological adjustment and coping in adults with prosthetic limbs. Behavioral Medicine, 25, 117124. http://dx.doi.org/10.1080/08964289909596741

Gallagher, P., \& MacLachlan, M. (2000a). The development and psychometric evaluation of the Trinity Amputation and Prosthesis Experience Scales (TAPES). Rehabilitation Psychology, 45, 130-154. http://dx.doi .org/10.1037/0090-5550.45.2.130

Gallagher, P., \& MacLachlan, M. (2000b). Positive meaning in amputation and thoughts about the amputated limb. Prosthetics and Orthotics International, 24, 196-204. http://dx.doi.org/10.1080/0309364000 8726548

Gallagher, P., \& MacLachlan, M. (2001). Adjustment to an artificial limb: A qualitative perspective. Journal of Health Psychology, 6, 85-100. http://dx.doi.org/10.1177/135910530100600107

Gallagher, P., \& MacLachlan, M. (2004). The Trinity Amputation and Prosthesis Experience Scales and quality of life in people with lowerlimb amputation. Archives of Physical Medicine and Rehabilitation, 85, 730-736. http://dx.doi.org/10.1016/j.apmr.2003.07.009

Gallagher, P., O’Donovan, M. A., Doyle, A., \& Desmond, D. (2011). Environmental barriers, activity limitations and participation restrictions experienced by people with major limb amputation. Prosthetics and Orthotics International, 35, 278-284. http://dx.doi.org/10.1177/ 0309364611407108

Habibović, M., van den Broek, K. C., Alings, M., Van der Voort, P. H., \& Denollet, J. (2012). Posttraumatic stress 18 months following cardioverter defibrillator implantation: Shocks, anxiety, and personality. Health Psychology, 31, 186-193. http://dx.doi.org/10.1037/a0024701

Han, B., Yan, B., Zhang, J., Zhao, N., Sun, J., Li, C., . . Chen, J. (2014). The influence of the social support on symptoms of anxiety and depression among patients with silicosis. The Scientific World Journal, 2014, Article ID 24804. http://dx.doi.org/10.1155/2014/724804

Hawamdeh, Z. M., Othman, Y. S., \& Ibrahim, A. I. (2008). Assessment of anxiety and depression after lower limb amputation in Jordanian patients. Neuropsychiatric Disease and Treatment, 4, 627-633. http://dx .doi.org/10.2147/NDT.S2541

Hobfoll, S. E., \& London, P. (1986). The relation ship of self-concept and social support to emotional distress among women during war. Journal of Social and Clinical Psychology, 4, 189-203. http://dx.doi.org/10 $.1521 /$ jscp.1986.4.2.189

Horgan, O., \& MacLachlan, M. (2004). Psychosocial adjustment to lowerlimb amputation: A review. Disability and Rehabilitation, 26, 837-850. http://dx.doi.org/10.1080/09638280410001708869

Horta, C., Vilaverde, J., Mendes, P., Gonçalves, I., Serra, L., Pinto, P. S., . . Serra, M. B. (2003). Avaliação da taxa de amputações. Consulta multidisciplinar do pé diabético [Evaluation of diabetic foot amputation rate]. Acta Medica Portuguesa, 16, 373-380.

Hu, L. T., \& Bentler, P. M. (1999). Cutoff criteria for fit indexes in covariance structure analysis: Conventional criteria versus new alternatives. Structural Equation Modeling, 6, 1-55. http://dx.doi.org/10.1080/ 10705519909540118

Iraj, B., Khorvash, F., Ebneshahidi, A., \& Askari, G. (2013). Prevention of diabetic foot ulcer. International Journal of Preventive Medicine, 4, 373-376.

Karanci, A. N., \& Dirik, G. (2003). Predictors of pre- and postoperative anxiety in emergency surgery patients. Journal of Psychosomatic Research, 55, 363-369. http://dx.doi.org/10.1016/S0022-3999(02)00631-1

Kline, R. B. (2011). Principles and practice of structural equation modeling. NewYork, NY: Guilford Press.

Leão, L., Abreu, S., Padrão, P., \& Lemos, P. (1995). Caracterização dos amputados da consulta externa do serviço de medicina física e reabilitação dos HUC [Characterization of the amputees of the external consultation of the physical medicine service and rehabilitation of the HUC] (pp. 3-5). Coimbra, Portugal: Medicina Física e Reabilitação.
Leung, H. B., Wong, W. C., Wu, F. C. J., \& Guerin, J. S. (2004). Perioperative and rehabilitation outcome after lower-limb amputation in elderly Chinese patients in Hong Kong. Journal of Orthopaedic Surgery, 12, 102-109. http://dx.doi.org/10.1177/230949900401200119

Livneh, H. (1986). A unified approach to existing models of adaptation to disability: I. A model of adaptation. Journal of Applied Rehabilitation Counseling, 17, 5-16.

Livneh, H. (2001). Psychosocial adaptation to chronic illness and disability: A conceptual framework. Rehabilitation Counseling Bulletin, 44 151-160. http://dx.doi.org/10.1177/003435520104400305

Livneh, H., \& Antonak, R. F. (1997). Psychosocial adaptation to chronic illness and disability. Gaithersburg, MD: Aspen.

Livneh, H., \& Antonak, R. F. (1999). Psychosocial aspects of chronic illness and disability. In F. Chan \& M. J. Leahy (Eds.), Health care and disability case management (pp. 121-168). Lake Zurich, IL: Vocational Consultants Press.

Livneh, H., Antonak, R. F., \& Gerhardt, J. (1999). Psychosocial adaptation to amputation: The role of sociodemographic variables, disabilityrelated factors and coping strategies. International Journal of Rehabilitation Research, 22, 21-32. http://dx.doi.org/10.1097/00004356-19 9903000-00003

Livneh, H., Antonak, R. F., \& Gerhardt, J. (2000). Multidimensional investigation of the structure of coping among people with amputations. Psychosomatics, 41, 235-244. http://dx.doi.org/10.1176/appi.psy.41.3 .235

Livneh, H., \& Wilson, L. M. (2003). Coping strategies as predictors and mediators of disability-related variables and psychosocial adaptation: An exploratory investigation. Rehabilitation Counseling Bulletin, 46, 194 208. http://dx.doi.org/10.1177/003435520304600401

Ljungberg, I., Kroll, T., Libin, A., \& Gordon, S. (2011). Using peer mentoring for people with spinal cord injury to enhance self-efficacy beliefs and prevent medical complications. Journal of Clinical Nursing, 20, 351-358. http://dx.doi.org/10.1111/j.1365-2702.2010.03432.x

Machado-Vaz, I., Roque, V., Pimentel, S., Rocha, A., \& Duro, H. (2012). Caracterização psicossocial de uma população Portuguesa de amputados do membro inferior [Psychosocial characterization of a Portuguese sample of lower limb amputees]. Acta Medica Portuguesa, 25, 77-82.

Mahoney, F. I., \& Barthel, D. W. (1965). Functional evaluation: The Barthel Index. Maryland State Medical Journal, 14, 61-65.

Martz, E., \& Cook, D. W. (2001). Physical impairments as risk factors for the development of posttraumatic stress disorder. Rehabilitation Counseling Bulletin, 44, 217-221. http://dx.doi.org/10.1177/003435520 104400404

Mollaoglu, M. (2006). Perceived social support, anxiety, and self-care among patients receiving hemodialysis. Dialysis \& Transplantation, 35, 144-155. http://dx.doi.org/10.1002/dat.20002

Monteiro-Soares, M., \& Dinis-Ribeiro, M. (2014). Portugal meets Eurodiale: Better late than never. Diabetes Research and Clinical Practice, 106, e83-e85. http://dx.doi.org/10.1016/j.diabres.2014.09.030

Moxey, P. W., Gogalniceanu, P., Hinchliffe, R. J., Loftus, I. M., Jones, K. J., Thompson, M. M., \& Holt, P. J. (2011). Lower extremity amputations-A review of global variability in incidence. Diabetic Medicine, 28, 1144-1153. http://dx.doi.org/10.1111/j.1464-5491.2011.03279.x

Oaksford, K., Frude, N., \& Cuddihy, R. (2005). Positive coping and stress-related psychological growth following lower limb amputation. Rehabilitation Psychology, 50, 266-277. http://dx.doi.org/10.1037/ 0090-5550.50.3.266

Olobatuyi, M. E. (2006). A user's guide to path analysis. Lanham, MD: University Press of America.

Organization for Economic Cooperation and Development (OECD)/ European Union (EU). (2016). Diabetes prevalence. In OECD/EU, Health at a glance: Europe 2016: State of health in the EU cycle (pp. 80-81.) Paris, France: OECD Publishing. http://dx.doi.org/10.1787/ 9789264265592-en 
Pais-Ribeiro, J. L. P. (1999). Escala de satisfação com o suporte social (ESSS) [Satisfaction with Social Support Scale]. Análise Psicológica, 3, $547-558$.

Pais-Ribeiro, J. L., \& Santos, C. (2001). Estudo conservador de adaptação do Ways of Coping Questionnaire a uma amostra e contexto portugueses [Conservative study of adaptation of the Ways of Coping Questionnaire to a Portuguese sample and context]. Análise Psicológica, 4, 491-502.

Pais-Ribeiro, J., Silva, I., Ferreira, T., Martins, A., Meneses, R., \& Baltar, M. (2007). Validation study of a Portuguese version of the Hospital Anxiety and Depression Scale. Psychology, Health \& Medicine, 12, 225-237. http://dx.doi.org/10.1080/13548500500524088

Pereira, M. G., Figueiredo, A. P., \& Fincham, F. D. (2012). Anxiety, depression, traumatic stress and quality of life in colorectal cancer after different treatments: A study with Portuguese patients and their partners. European Journal of Oncology Nursing, 16, 227-232. http://dx.doi.org/ 10.1016/j.ejon.2011.06.006

Pereira, M. G., \& Pedras, S. (2016). Versão do IES-R adaptada à amputação [IES-R version adapted to amputation]. Braga, Portugal: Versão do Grupo de Investigação em Saúde Familiar \& Doença. Escola de Psicologia, Universidade do Minho.

Pereira, M. G., Pedras, S., Machado, J. C., \& Ferreira, G. (2016). Partners' representations of diabetes as mediators between patients' representations and adherence to self-care behaviors, in type 2 diabetes. Psychology, Health \& Medicine, 21, 707-714. http://dx.doi.org/10.1080/ 13548506.2015.1118517

Pereira, M. G., Vilhena, E., \& Pedras, S. (2016). Versão adaptada do TAPES-R: Versão sem prótese [TAPES-R adapted version: Limb Loss Version without prosthesis]. Braga, Portugal: Versão do Grupo de Investigação em Saúde Familiar \& Doença. Escola de Psicologia, Universidade do Minho.

Phelps, L. F., Williams, R. M., Raichle, K. A., Turner, A. P., \& Ehde, D. M. (2008). The importance of cognitive processing to adjustment in the 1st year following amputation. Rehabilitation Psychology, 53, $28-$ 38. http://dx.doi.org/10.1037/0090-5550.53.1.28

Pinto, P. R., McIntyre, T., Ferrero, R., Almeida, A., \& Araújo-Soares, V. (2013). Predictors of acute postsurgical pain and anxiety following primary total hip and knee arthroplasty. The Journal of Pain, 14, 502-515. http://dx.doi.org/10.1016/j.jpain.2012.12.020

Portuguese Society of Diabetes (PSD). (2016). Diabetes: Factos e números 2015: Relatório Anual do Observatório Nacional da Diabetes 2016 [Diabetes: Facts and numbers 2015: Annual report from National Observatory of Diabetes 2016]. Retrieved from: https://www.dgs.pt/ estatisticas-de-saude/estatisticas-de-saude/publicacoes/diabetes-factose-numeros-7-edicao.aspx

Preacher, K. J., \& Kelley, K. (2011). Effect size measures for mediation models: Quantitative strategies for communicating indirect effects. Psychological Methods, 16, 93-115. http://dx.doi.org/10.1037/a0022658

Quadros, L. (2010). A prevalência e a repercussão psicológica e funcional da dor e sensação fantasma na amputação do membro inferior por isquémia avançada [The prevalence and psychological and functional repercussion of pain and phantom sensation in lower limb amputation by advanced ischemia] (Master thesis). Retrieved from http://repositorio.ul .pt/handle/10451/1977

Ramos, C. S. M. (2011). Dependência funcional, morbilidade psicológica, sintomatologia traumática, coping e satisfação com a vida em amputados do membro inferior [Functional Dependence, Psychological Morbidity, Traumatic Symptomatology, Coping and Life Satisfaction in Amputees of the Lower Limb] (Master's thesis). Retrieved from http://hdl.handle .net/1822/20829

Rybarczyk, B., Nicholas, J. J., \& Nyenhuis, D. L. (1997). Coping with a leg amputation: Integrating research and clinical practice. Rehabilitation Psychology, 42, 241-256. http://dx.doi.org/10.1037/0090-5550.42.3.241

Rybarczyk, B., Nyenhuis, D. L., Nicholas, J. J., Cash, S. M., \& Kaiser, J. (1995). Body image, perceived social stigma, and the prediction of psychosocial adjustment to leg amputation. Rehabilitation Psychology, 40, 95-110. http://dx.doi.org/10.1037/0090-5550.40.2.95

Rybarczyk, B. D., Nyenhuis, D. L., Nicholas, J. J., Schulz, R., Alioto, R. J., \& Blair, C. (1992). Social discomfort and depression in a sample of adults with leg amputations. Archives of Physical Medicine and Rehabilitation, 73, 1169-1173.

Rzeszutek, M., Oniszczenko, W., \& Firlag-Burkacka, E. (2012). Temperament traits, coping style and trauma symptoms in HIV + men and women. AIDS Care, 24, 1150-1154. http://dx.doi.org/10.1080/ 09540121.2012 .687819

Rzeszutek, M., Oniszczenko, W., Schier, K., Biernat-Kałuża, E., \& Gasik, R. (2015). Trauma symptoms, temperament traits, social support and the intensity of pain in a Polish sample of patients suffering from chronic pain. Personality and Individual Differences, 83, 13-17. http://dx.doi .org/10.1016/j.paid.2015.03.036

Rzeszutek, M., Oniszczenko, W., Schier, K., Biernat-Kałużac, E., \& Gasik, R. (2016). Temperament traits, social support, and trauma symptoms among HIV/AIDS and chronic pain patients. International Journal of Clinical and Health Psychology, 16, 137-146. http://dx.doi.org/10.1016/ j.ijchp.2015.10.001

Satorra, A., \& Bentler, E. M. (1994). Corrections to test statistics and standard errors in covariance structure analysis. In A. von Eye \& C. C. Clogg (Eds.), Latent variables analysis: Applications for development research (pp. 339-419). Thousand Oaks, CA: Sage.

Schneiderman, N., Ironson, G., \& Siegel, S. D. (2005). Stress and health: Psychological, behavioral, and biological determinants. Аnпиal Review of Clinical Psychology, 1, 607-628. http://dx.doi.org/10.1146/annurev .clinpsy.1.102803.144141

Schokker, M. C., Stuive, I., Bouma, J., Keers, J. C., Links, T. P., Wolffenbuttel, B. H. R., . . . Hagedoorn, M. (2010). Support behavior and relationship satisfaction in couples dealing with diabetes: Main and moderating effects. Journal of Family Psychology, 24, 578-586. http:// dx.doi.org/10.1037/a0021009

Schoppen, T., Boonstra, A., Groothoff, J. W., de Vries, J., Göeken, L. N., \& Eisma, W. H. (2003). Physical, mental, and social predictors of functional outcome in unilateral lower-limb amputees. Archives of Physical Medicine and Rehabilitation, 84, 803-811. http://dx.doi.org/10 .1016/S0003-9993(02)04952-3

Senra, H. (2013). How depressive levels are related to the adults' experiences of lower-limb amputation: A mixed methods pilot study. International Journal of Rehabilitation Research, 36, 13-20. http://dx.doi.org/ 10.1097/MRR.0b013e328356429d

Senra, H., Oliveira, R. A., Leal, I., \& Vieira, C. (2012). Beyond the body image: A qualitative study on how adults experience lower limb amputation. Clinical Rehabilitation, 26, 180-191. http://dx.doi.org/10.1177/ 0269215511410731

Singh, R., Hunter, J., \& Philip, A. (2007). The rapid resolution of depression and anxiety symptoms after lower limb amputation. Clinical Rehabilitation, 21, 754-759. http://dx.doi.org/10.1177/0269215507077361

Sinha, R., van den Heuvel, W. J. A., \& Arokiasamy, P. (2014). Adjustments to amputation and an artificial limb in lower limb amputees. Prosthetics and Orthotics International, 38, 115-121. http://dx.doi.org/ 10.1177/0309364613489332

Springer, C., \& Padgett, D. K. (2000). Gender differences in young adolescents' exposure to violence and rates of PTSD symptomatology. American Journal of Orthopsychiatry, 70, 370-379. http://dx.doi.org/10 $1037 / \mathrm{h} 0087637$

Srivastava, K., \& Chaudhury, S. (2014). Rehabilitation after amputation: Psychotherapeutic intervention module in Indian scenario. The Scientific World Journal, 2014, Article ID 469385. http://dx.doi.org/10.1155/ 2014/469385

Traballesi, M., Brunelli, S., Pratesi, L., Pulcini, M., Angioni, C., \& Paolucci, S. (1998). Prognostic factors in rehabilitation of above knee 
amputees for vascular diseases. Disability and Rehabilitation, 20, 380384. http://dx.doi.org/10.3109/09638289809166097

Traballesi, M., Paolucci, S., Lubich, S., Pratesi, L., \& Brunelli, S. (1995). Nontraumatic above-knee amputation in elderly patients. Results of rehabilitation and prognostic factors. Europa Medicophysica, 31, 21-26.

Trief, P. M., Grant, W., Elbert, K., \& Weinstock, R. S. (1998). Family environment, glycemic control, and the psychosocial adaptation of adults with diabetes. Diabetes Care, 21, 241-245. http://dx.doi.org/10 .2337/diacare.21.2.241

van de Weg, F. B., \& van der Windt, D. A. (2005). A questionnaire survey of the effect of different interface types on patient satisfaction and perceived problems among trans-tibial amputees. Prosthetics and Orthotics International, 29, 231-239. http://dx.doi.org/10.1080/0309 3640500199679

Wan Hazmy, C. H., Chia, W. Y., Fong, T. S., \& Ganendra, P. (2006). Functional outcome after major lower extremity amputation: A survey on lower extremity amputees. The Medical Journal of Malaysia, 61(Suppl. A), 3-9.

Wegener, S. T., Hofkamp, S. E., \& Ehde, D. M. (2008). Interventions for psychological issues in amputation: A team approach. In P. Gallagher, D. M. Desmond, \& M. MacLachlan (Eds.), Psychoprosthetics (pp. 91-105). London, UK: Springer. http://dx.doi.org/10.1007/978-184628-980-4 7
Weiss, D. S., \& Marmar, C. R. (1997). The Impact of Event Scale-Revised. In J. Peterson \& M. Teerence (Eds.), Assessing psychological trauma and PTSD (pp. 399-411). New York, NY: Guilford Press.

Wiedemar, L., Schmid, J. P., Müller, J., Wittmann, L., Schnyder, U., Saner, H., \& von Känel, R. (2008). Prevalence and predictors of posttraumatic stress disorder in patients with acute myocardial infarction. Heart \& Lung, 37, 113-121. http://dx.doi.org/10.1016/j.hrtlng.2007.03.005

Williams, R. M., Ehde, D. M., Smith, D. G., Czerniecki, J. M., Hoffman, A. J., \& Robinson, L. R. (2004). A two-year longitudinal study of social support following amputation. Disability and Rehabilitation, 26, 862874. http://dx.doi.org/10.1080/09638280410001708878

Williamson, G. M. (1995). Restriction of normal activities among older adult amputees: The role of public self-consciousness. Journal of Clinical Geropsychology, 1, 229-242.

Zigmond, A. S., \& Snaith, R. P. (1983). The hospital anxiety and depression scale. Acta Psychiatrica Scandinavica, 67, 361-370. http://dx.doi .org/10.1111/j.1600-0447.1983.tb09716.x

Received March 29, 2017

Revision received September 1, 2017

Accepted September 25, 2017 